\title{
An Investigation Into the Beneficial Effects of High- Dose Interferon beta 1-a, Compared to Low-Dose Interferon Beta 1-a (the base therapeutic regimen) in moderate to severe COVID-19
}

llad Alavi Darazam ( $D$ ilad13@yahoo.com)

Shahid Beheshti University of Medical Sciences

Firouze Hatami

Shahid Beheshti University of Medical Sciences

Mohammad Mahdi Rabiei

Shahid Beheshti University of Medical Sciences

Mohamad Amin Pourhoseingholi

Shahid Beheshti University of Medical Sciences

Minoosh Shabani

Shahid Beheshti University of Medical Sciences

Shervin Shokouhi

Shahid Beheshti University of Medical Sciences

Omid Moradi

Shahid Beheshti University of Medical Sciences

Farid Javandoust Gharehbagh

Shahid Beheshti University of Medical Sciences

Nasrinsadat Mirtalaee

Shahid Beheshti University of Medical Sciences

Halimeh Negahban

Shahid Beheshti University of Medical Sciences

Mahdi Amirdosara

Shahid Beheshti University of Medical Sciences

Masoud Zangi

Shahid Beheshti University of Medical Sciences

Mohammadreza Hajiesmaeili

Shahid Beheshti University of Medical Sciences

Muhanna Kazempour

Shahid Beheshti University of Medical Sciences

Navid Shafigh

Shahid Beheshti University of Medical Sciences 


\section{Research Article}

Keywords: COVID-19, SARS-COV-2, Randomized controlled trial, lopinavir/ritonavir, Interferon- $\beta$ 1a

Posted Date: January 21st, 2021

DOl: https://doi.org/10.21203/rs.3.rs-138540/v2

License: (c) (1) This work is licensed under a Creative Commons Attribution 4.0 International License. Read Full License 


\section{Abstract}

Introduction: Coronavirus disease 2019 (COVID-19) has been a serious obstacle in front of public health. Interferon-beta 1a (IFN- $\beta$ 1a) has been used to treat patients with COVID-19. We aimed to compare the effectiveness of high-dose IFN- $\beta$ 1a compared to low dose IFN- $\beta$ 1a in moderate to severe COVID-19 cases.

Methods: In this randomized, controlled, and clinical trial, eligible patients with confirmed SARS-CoV-2 infections were randomly assigned to receive one of the two following therapeutic regimens: The intervention group was treated with high-dose IFN- $\beta$ 1a (Recigen) (Subcutaneous injections of $88 \mu \mathrm{g}$ $(24,000 \mathrm{IU})$ on days $1,3,6)+$ lopinavir / ritonavir (Kaletra) and the control group was treated with low-dose IFN- $\beta$ 1a (Recigen) (Subcutaneous injections of $44 \mu \mathrm{g}(12,000 \mathrm{IU})$ on days $1,3,6)+$ lopinavir /ritonavir (Kaletra) (400mg/100 mg twice a day for 10 days, orally, in two groups).

Result: A total of 168 COVID- 19 confirmed patients underwent randomization; 83 were assigned to the intervention group and 85 were assigned to the control group. Median Time To Clinical Improvement (TTIC) for cases treated with low-dose IFN- $\beta 1$ a was shorter than that for cases treated with high-dose IFN$\beta 1$ a (6 vs10 days). Due to differences between some baseline clinical factors between intervention and control group, we performed an adjusted analysis. The model failed to reach a significant difference between two groups.

Conclusion: The use of high-dose IFN- $\beta$ 1a did not improve TTCI in hospitalized patients with moderate to severe COVID-19. Also, it did not have any significant effect on mortality reduction compared with treating with low-dose IFN- $\beta$ 1a.

Trial registration: The trial was confirmed by the Ethics in Medical Research Committee of the Shahid Beheshti University of Medical Sciences. Signed informed consents were obtained from all the participants or their legally authorized representatives. This trial has been registered as ClinicalTrials.gov, NCT04521400.

\section{Introduction}

Coronavirus disease 2019 (COVID-19) has still been challenging and remained as a major barrier against healthcare providers. High contagion rate as well as wide spread of infection have prompted World health organization (WHO) to declare a pandemic situation on March $11^{\text {th }}, 2020$. As of 18 November, more than 55 million confirmed cases of COVID-19 and 1,328,000 deaths were reported in the world [1] . COVID-19 also known as severe acute respiratory syndrome coronavirus 2 (SARS-CoV-2) belongs to betacoronaviruses genus and Coronaviridae family in the order of Nidovirales. SARS-CoV-2 was reported as the sister clade to the SARS-CoV by International Committee on Taxonomy of Viruses [2]. COVID-19 shares $80 \%$ genomic identity with SARS-CoV, but additional gene regions were detected in COVID-19 genome using genomic analyses [3]. 
Proper immunity and inflammation are crucial steps in restricting various pathogens. On the other hand, brisk and dysregulated inflammation due to infection may exerts deleterious consequences on various organs $[4,5]$. Cytokine storm, deregulated release of cytokines, is a hallmark in patients with severe COVID-19 associated with multi-organ failure and high mortality [6]. Immunomodulatory agents for tackling dysregulated immune response are treatment choices for COVID-19. Of various immunomodulatory agents, interferons (IFNs) exert a broad range of influences on immune system including antiviral, antiproliferative and immunomodulatory activities [7]. IFNs, a group of soluble glycoproteins, are produced by certain cells in response to virus, bacteria, and tumor cells [8]. They are segregated into three major types including type I IFN (mainly alpha and beta), type II IFN(gamma) and type III IFN (lambda) [9]. It has been shown that IFN- $\beta$ contributed to robust inhibition of coronaviruses as opposed to IFN- $\alpha$. IFN- $\beta 1 \mathrm{a}$ and IFN- $\beta 1 \mathrm{~b}$ also exhibited impressive antiviral effect against SARS-CoV and MERS-CoV $[10,11]$. In vitro and In vivo studies also confirmed beneficial effect of IFN- $\beta$ 1a against coronavirus including avian infectious bronchitis virus, murine hepatitis virus and SARS-CoV [12]. As reported by a recent In vitro study, IFN- $\beta 1$ a also could reduce SARS-CoV-2 replication rate [13]. Effect of INFs administration as a potential treatment for COVID-19 cases has been studied, but there is still no consensus on effective dose of INFs as a treatment of infection.

To date, the lack of promising treatment for COVID-19 has made many demands on healthcare systems. Therefore, intensive efforts for identifying promising antiviral drugs are urgent needs. In this study we; therefore, performed a single-center, randomized, open-label, controlled trial to investigate the efficacy and safety of high-dose IFN- $\beta 1$ in in combination with lopinavir/ritonavir compared with low-dose IFN- $\beta$ 1a in combination with lopinavir/ritonavir (the base therapeutic regimen) in moderate to severe COVID-19 patients.

\section{Material And Methods}

\section{Trial Design and Oversight}

In this single-center, open-label, randomized, controlled, parallel-group and clinical trial, eligible patients with confirmed SARS-CoV-2 infections were randomly assigned in a 1:1 ratio to receive one of the following therapeutic regimens: 1) IFN- $\beta 1$ a (Recigen) (Subcutaneous injections of $88 \mu \mathrm{g}(24,000 \mathrm{IU})$ on days $1,3,6)+$ lopinavir/ritonavir (Kaletra) [intervention group], 2) IFN- 31 a (Recigen) (Subcutaneous injections of $44 \mu \mathrm{g}(12,000 \mathrm{IU})$ on days $1,3,6)+$ lopinavir/ritonavir (Kaletra) $(400 \mathrm{mg} / 100 \mathrm{mg}$ twice a day for 10 days, orally, in all two arms) [control group]. Intervention and control groups received standards of care including necessary oxygen support and non-invasive or invasive mechanical ventilation. The study was commenced at August $20^{\text {th }}$ and terminated at September $4^{\text {th }}, 2020$ at Loghman Hakim hospital.

We tried to collect our data on a potential treatment regimen by performing a pragmatic randomized controlled trial for moderate to severe COVID-19 patients without sacrificing any critical investigational component in a reasonable time frame. 
Due to emergency situation as well as increased rate of infected patients, blinding of all caregivers was not possible. All patients and outcome assessor were blinded to the arms of study. Deputy of the vice chancellor of research and technology in Shahid Beheshti University of Medical Sciences provided all the supports.

All patients were randomly assigned to each arm of the study via permuted block randomization (each block-sized for three or six patients) in order to minimize allocation bias in each studied group. The sequence of the randomization was generated via "randomizeR" package using R project for statistics computing version 3.6.1 (R Foundation for Statistical Computing, Vienna, Austria). All randomization codes for individuals enrolled to the study, were sealed in unrecognizable opaque envelopes by the responsible statistician for randomization. The investigator (IAD, MMR, and FH) enrolled the patients and only then open envelopes to assign patients to the different treatment groups. This method of allocation concealment leads to minimizing selection and confounding biases.

The Ethics in Medical Research Committee of the Shahid Beheshti University of Medical Sciences had been confirmed the study. Signed informed consents were obtained from all participants or their legally authorized representatives. The trial was carried out under the declaration of Helsinki and the International Conference on Harmonization of Good Clinical Practice (ICH-GCP) guidelines for the conduct of clinical trials on human participants. The trial has been registered with ClinicalTrials.gov, NCT04521400 and the full protocol is freely available on the BMC Trials [14].

\section{Patients}

In this randomized controlled trial, patients were assigned to the intervention group or the control group. The inclusion criteria were as follow: age $\geq 18$ years, oxygen saturation (SPO2) $\leq 93 \%$ or respiratory rate $\geq 24$, presence of at least one of following manifestations on admission: Cough, shortness of breath, nasal congestion/ discharge, myalgia/arthralgia, radiation contactless body temperature $\geq 37.8$, diarrhea/vomiting and headache or fatigue. The patients' symptoms must be in acute phase ( $\leq 14$ days).

Exclusion criteria were refusal to participate, receiving drugs with interactions with lopinavir/ritonavir or Interferon- $\beta 1 \mathrm{a}$, a fivefold rise in serum AST/ALT relative to upper limit of normal laboratory results, pregnant or lactating women, history of alcohol or drug addiction in the past 5 years and intubated less than one hour after admission to the hospital.

\section{Clinical and Laboratory Monitoring}

For assuring safety, daily monitoring for adverse effects (AEs) and treatment-related AEs, vital signs (pulse rate, respiratory frequency, body temperature, and blood pressure), spo2, Glasgow Coma Scale (GCS) and laboratory tests was performed. Time, severity, symptoms of adverse effects and their relation with aforementioned drugs on a daily basis were recorded.

Before enrollment, nasopharyngeal swab samples were obtained from each patient. The samples were tested using RT-PCR kits including Liferiver (W-RR-0479-02, China) for E, N, and Rdrp genes. Patients' data 
were recorded on paper checklists and Hospital Information System (HIS) by FH and MMR. The recorded data were entered into a pre-designed EXCEL sheet and later confirmed by a third investigator (IAD).

\section{Clinical and Laboratory Monitoring}

For assuring safety, daily monitoring for adverse effects (AEs) and treatment-related AEs, vital signs (pulse rate, respiratory frequency, body temperature, and blood pressure), spo2, Glasgow Coma Scale (GCS) and laboratory tests was performed. Time, severity, symptoms of adverse effects and their relation with aforementioned drugs on a daily basis were recorded.

Before enrollment, nasopharyngeal swab samples were obtained from each patient. The samples were tested using RT-PCR kits including Liferiver (W-RR-0479-02, China) for E, N, and Rdrp genes. Patients' data were recorded on paper checklists and Hospital Information System (HIS) by FH and MMR. The recorded data were entered into a pre-designed EXCEL sheet and later confirmed by a third investigator (IAD).

\section{Outcome Measures}

Primary outcome measure was TTCI defined as the time from enrollment to discharge or decline of two steps on the seven-step ordinal scale. Beigel and colleagues in a posthoc analysis of an influenza study introduced a six-step ordinal scale. WHO R\&D Blueprint Team (Accessed May 15, 2020, at https://www.who.int/teams/blueprint/covid-19) have recommended a nine-step ordinal scale for COVID19. In the current study the utilized seven-step ordinal scale consists of the subsequent categories: (I) Not hospitalized, and has no activity limitations; (II) Not hospitalized, but has activity limitations; (III) Hospitalized, but does not need any supplemental oxygen; (IV) Hospitalized, and needs supplemental oxygen; (V) Hospitalized, and needs either High-Flow Nasal Cannula (HFNC) or non-invasive ventilation; (VI) Hospitalized, and needs invasive ventilation; and (VII) Dead.

Secondary outcomes include mortality from the date of randomization until day 21 , by which all of the patients had at least one of the following outcomes: 1) A decline of two steps on the seven-step ordinal scale, 2) Hospital discharge or 3) Death. Sp02 improvement defined as the difference between the last and the first recorded measurement during the hospitalization, using pulse oximetry; length of stay in the hospital until the date of discharge from hospital or death from any cause, whichever came first; the incidence of new mechanical ventilation uses from the date of randomization until day 21. Follow-ups of discharged patients were done by utilizing telemedicine visits, online, or over the telephone.

\section{Statistical Analysis:}

Total sample size was calculated according to the Latouche and colleagues' approach for estimating sample size in survival analyses with $90 \%$ power, alpha $=0.05$, Hazard Ratio (HR) of 2.0 (as the ratio of the hazard rates of TTCl) and assuming that $60 \%$ of patients would reach the primary outcome. The calculations were carried out using Package 'powerSurvEpi' in R and accounted for a dropout rate of $10 \%$. According to above-mentioned assumptions, 168 patients should have been recruited for this trial. 
Patients who failed to reach the primary endpoint (TTCI) or died prior to day 21 were regarded as rightcensored in analysis.

Kaplan-Meier (compared with a log-rank test) was used to analyze the TTCI. Cox proportional-hazards model was also applied to calculate the HRs with 95\% Confidence Intervals (Cls). All the participants who had undergone randomization were included in Intention-To-Treat (ITT) analysis (figure 1).

For categorical variables frequencies and percentage were employed. For distributed continuous variables Mean (SD) and for none-normally distributed variables, median (interquartile range) were used, respectively. Categorical variables were analyzed using chi-squared or the Fisher's exact test (when the expected frequency was less than 5 in one or more cells). Continuous variables were evaluated using Ttest (for normally distributed) and Mann-Whitney $U$ test (for non-normally distributed). A p-value of $<0.05$ was considered to be statistically significant. All of the carried-out tests were two-tailed. R software version 3.6.1 was used to perform the statistical analyses.

\section{Results}

\section{Patients:}

Of 410 patients with positive RT-PCR and/or chest CT scan, 168 patients with moderate to severe COVID19 were recruited in the trial. Control group is comprised of 85 patients treated with low-dose IFN- $\beta$ 1a and 83 patients were included in intervention group (treated with high-dose IFN- $\beta$ 1a). The flowchart for the study was depicted in figure 1. Mean \pm SD for participants was $59.9 \pm 16.5$. Percentages of male and female participants were $61.9 \%$ and $38.1 \%$, respectively. Demographic and clinical baseline information for control and intervention group were outlined in Table 1. Majority of clinical factors failed to reach a significant difference between two studied groups at baseline. However, some risk factors including spo2, ferritin, D-dimer were significantly different between two groups at baseline $(p<0.05)$. In intervention group, the frequency of cases with D-dimer $>1000 \mathrm{ng} / \mathrm{nl}$ and spo $2<90 \%$ were significantly higher than those in control group (for D-dimer $19.3 \%$ vs $3.1 \%$; for Spo $294 \%$ vs $81.2 \%$ ).

\section{Primary Outcome:}

Median TTIC for cases treated with low-dose IFN- $\beta 1$ a was shorter than that for cases treated with highdose IFN- $\beta 1$ a ( 6 vs 10 days; $P=0.018$ ) (Table 2 ). In the Cox regression model, HR was 1.56 (95\% Cl: 1.052.30, P-value $=0.026)$.

Due to differences between some clinical factors between intervention and control group at baseline, we performed an adjusted analysis by including spo2, D-dimer and CRP in Cox regression model. The model failed to reach a significant difference between two groups. The adjusted HR was 1.37 (95\% Cl: 0.88-2.12, P-value=0.16).

\section{Secondary Outcome:}


In this study, of 168 participants, total mortality number was 65 . The mortality rates in intervention and control group were $34(41 \%)$ and 31 (36.5\%), respectively. No significant difference was found in terms of mortality rate between two groups. Length of stay in hospital for intervention group was longer than that in control group (table 2). Intervention group exhibited lower oxygen saturation and respiratory rate compared with control group $(\mathrm{P}=0.017)$. Rest of clinical factors were outlined in table 2 .

\section{Safety:}

Table 3 outlines adverse events in the safety population. In the intervention group, the prevalence of skin rash was significantly higher compared to control group (13.3\% vs .35\%). On the other hand, in the control group, the number of cases with leukopenia, hypo-albuminemia and severe anemia were significantly higher relative to the intervention group (table 3).

\section{Discussion}

In the current study, our major finding was that the high-dose IFN- $\beta 1$ a administration not only was not associated with lower mortality but also increased the length of stay in hospital as opposed to low-dose IFN- $\beta$ 1a administration. Based on clinical records, better outcome (proper oxygen saturation) was observed in patients treated with low-dose interferon.

INFs have different types with potent immunomodulatory and antiviral effects. IFN- $\beta$ as a type 1 interferon has been used to treat immune medicated disorders due to its immune regulatory properties. In the course of viral infection, interferon expression is associated with robust host defense against the viral phase of the infection [15]. Inherited errors in INFs genes resulting in diminished proper levels of IFNs or presence of autoantibodies against IFNs was associated with easy spread of viruses. Hence, IFNs paly crucial roles in minimizing the extent of severe infections. In a recent study, it has been shown that defects in interferon genes as well as core genes responsible for production of molecules in interferon amplification pathway, were associated with severe COVID-19. Therefore, type one INF administration in cases with severe COVID-19 was recommended by the investigator[16]. Antiviral effects of various agents against coronaviruses have been studied. Of various types of INFs, the most significant antiviral effect against MERS-CoV has been mentioned for INF $\beta$ subgroup $[17,18]$. Among various types of INFs, IFN- $\beta$ $1 \mathrm{a}$ has been associated with clinical efficacy compared to IFN- $\beta$ 1b in the treatment of COVID-19 [19].

In our study, results revealed that the mortality rate was not statistically different between patients treated with high- and low-dose IFN- $\beta 1 \mathrm{a}$. On the other hand, prolonged hospital stay and improper oxygenation status were observed in patients treated with high-dose IFN- $\beta$ 1a. It is of note to consider that intervention group had lower oxygen saturation at baseline. In addition, clinical and laboratory parameters including respiratory rate, heart rate, ferritin, D-dimer were significantly different between two studied groups at baseline. An adjusted analysis conducted by including spo2, D-dimer, and CRP in a Cox regression model, exhibited that there was no statistically significant difference between two groups. Difference in length of hospital stay between two groups was another impressive finding. It is obvious that prolonged length of hospitalization is associated with increased risk of complication and secondary infections. Moreover, it 
definitely places financial burden on either patient or healthcare systems. A more severe course could be associated with a longer duration of hospitalization. Furthermore, we should consider differences at baseline characteristics of our patients which also reflected the severity of disease.

In previous studies, some conflicting data have been reported. In a randomized placebo-controlled study on adult patients with moderate to severe COVID-19, IFN- $\beta$ 1a intravenous administration (10 $\mu \mathrm{g}$ per day; for 6 days) was not associated with better clinical outcome [20]. An obvious difference between our trial and theirs was the dose of administrated IFN- $\beta$ 1a. In another open-label randomized trial in Hong Kong, early ( $\leq 7$ days) administration of IFN- $\beta$ 1a by the dose of 8 million international units in combination with antiviral therapy was associated with reduction in duration of viral shedding, symptoms alleviation and reduced hospital stay [21]. This study; however, enrolled patients with mild to moderate disease and it was not designed as a placebo-controlled study. Interim results from the largest randomized control trial on COVID-19, coordinated by the World Health Organization therapeutics indicated that IFN- $\beta$ 1a have little or no effect on 28-day mortality or in-hospital course of COVID-19 among hospitalized patients [22].

High-dose IFN- $\beta 1$ a (12 million international units) was considered for treatment of other conditions such as immune-mediated diseases [23]. Number of clinical trials assessing the benefits of high-dose interferon beta 1a on patients with COVID-19 is scarce. In a study, it has been shown that addition of high-dose IFN- $\beta$ 1a to antiviral agents (lopinavir/ritonavir and hydroxychloroquine) was associated only with symptoms alleviation but the study had been conducted as a non-controlled clinical trial [24]. In our study, although majority of patient had severe COVID-19 infection, the total mortality rate was lower compared to other studies[25, 26]. Therefore, it can be assumed that IFN- $\beta$ 1a could be effective in COVID-19 treatment.

By administering higher doses of IFN, we expect to experience some adverse reactions dominantly. For instance, Higher doses can lead to hepatic toxicity. Therefore, In this case dose reduction policy should be considered[27]. Administration of lopinavir/ritonavir was also associated with hepatic toxicity and liver enzymes elevation [28]. Hence, we were uncertain that interferon administration was the cause of liver enzyme elevation. Moreover, we could not observe any difference in this regard between two groups.

In our study, skin rash was more prevalent in patients treated with high-dose IFN- $\beta$ 1a. Some serious hematologic adverse effects were observed more frequently in patients treated with low-dose IFN- $\beta 1 \mathrm{a}$. Hematologic side effects and bone marrow suppression are known adverse effects associated with interferon use [29]. It has been proven that these side effects are categorized as late adverse effects and are associated with the duration of exposure. However, in our study, leukopenia was more prevalent in control group. Owing to various other clinical factors which should be taken under consideration, we should not consider IFN- $\beta$ 1a administration as the only effective variable on hematologic findings in our study.

Limitations 
First and the most important limitation of the study is baseline characteristic variation. Although the study was designed as a prospective randomized clinical trial, because of limited sample size, different dispersion was observed in some baseline factors between two studied groups. Second, it was not possible to analyze arterial blood gas for some patients because of technical procedures limitation and trained staff limitation.

\section{Conclusion}

In this trial involving hospitalized patients with moderate to severe COVID-19, we did not find a significant difference in terms of mortality rate between groups treated with high- and low dose. The median TTCI was better in the control group compared with the intervention group.

\section{Declarations}

Ethics approval: The trial was confirmed by the Ethics in Medical Research Committee of the Shahid Beheshti University of Medical Sciences. signed informed consents were obtained from all the participants or their legally authorized representatives. This trial has been registered as ClinicalTrials.gov, NCT04521400.

Consent for publication: Not applicable

Availability of data and materials: The datasets generated during and/or analysed during the current study are available from the corresponding author on reasonable request.

Acknowledgments: The authors would like to thank the Clinical Research Development Unit (CRDU) of Loghman Hakim Hospital, Shahid Beheshti University of Medical Sciences, Tehran, Iran for their help and support in conducting this clinical trial.

Funding: Not applicable

Conflict of interests: We declare no competing interests

Acknowledgments: The authors would like to thank the Clinical Research Development Unit (CRDU) of Loghman Hakim Hospital, Shahid Beheshti University of Medical Sciences, Tehran, Iran for their support, cooperation and assistance throughout the period of study.

Authors' contributions: All authors contributed to conception and design of study; MMR, FH, IAD, contributed to the acquisition of data; MMR, FH, IAD and MAP contributed to the analysis of data; all authors contributed to the drafting of the article and/or critical revision; and all authors contributed to the final approval of manuscript.

\section{References}


1. World Health Organization(Who) [Available from: https://www.who.int/emergencies/diseases/novelcoronavirus-2019.

2. Abdelrahman Z, Li M, Wang X. Comparative review of SARS-CoV-2, SARS-CoV, MERS-CoV, and influenza a respiratory viruses. Frontiers in immunology. 2020;11:2309.

3. Caldaria A, Conforti C, Di Meo N, Dianzani C, Jafferany M, Lotti T, et al. COVID-19 and SARS: Differences and similarities. Dermatologic Therapy. 2020.

4. de la Rica R, Borges M, Gonzalez-Freire M. COVID-19: in the eye of the cytokine storm. Frontiers in Immunology. 2020;11:2313.

5. Jose RJ, Manuel A. COVID-19 cytokine storm: the interplay between inflammation and coagulation. The Lancet Respiratory Medicine. 2020.

6. Zheng H-Y, Zhang M, Yang C-X, Zhang N, Wang X-C, Yang X-P, et al. Elevated exhaustion levels and reduced functional diversity of $T$ cells in peripheral blood may predict severe progression in COVID19 patients. Cellular \& molecular immunology. 2020;17(5):541-3.

7. Wang BX, Fish EN, editors. Global virus outbreaks: Interferons as 1st responders. Seminars in immunology; 2019: Elsevier.

8. González-Navajas JM, Lee J, David M, Raz E. Immunomodulatory functions of type I interferons. Nature Reviews Immunology. 2012;12(2):125-35.

9. Österlund P, Veckman V, Sirén J, Klucher KM, Hiscott J, Matikainen S, et al. Gene expression and antiviral activity of alpha/beta interferons and interleukin-29 in virus-infected human myeloid dendritic cells. Journal of virology. 2005;79(15):9608-17.

10. Moriguchi H, Sato C. Treatment of SARS with human interferons. The Lancet. 2003;362(9390):1159.

11. Morra ME, Van Thanh L, Kamel MG, Ghazy AA, Altibi AM, Dat LM, et al. Clinical outcomes of current medical approaches for Middle East respiratory syndrome: A systematic review and meta-analysis. Reviews in medical virology. 2018;28(3):e1977.

12. Hensley LE, Fritz EA, Jahrling PB, Karp C, Huggins JW, Geisbert TW. Interferon- $\beta$ 1a and SARS coronavirus replication. Emerging infectious diseases. 2004;10(2):317.

13. Clementi N, Ferrarese R, Criscuolo E, Diotti RA, Castelli M, Scagnolari C, et al. Interferon- $\beta$ - 1 a Inhibition of Severe Acute Respiratory Syndrome-Coronavirus 2 In Vitro When Administered After Virus Infection. The Journal of infectious diseases. 2020;222(5):722-5.

14. Darazam IA, Hatami F, Rabiei MM, Pourhoseingholi MA, Moradi O, Shokouhi S, et al. An investigation into the beneficial effects of high-dose interferon beta 1-a, compared to low-dose interferon beta 1-a (the base therapeutic regimen) in moderate to severe COVID-19: A structured summary of a study protocol for a randomized controlled I trial. Trials. 2020;21(1):1-3.

15. Samuel CEJCmr. Antiviral actions of interferons. 2001;14(4):778-809.

16. Zhang Q, Bastard P, Liu Z, Le Pen J, Moncada-Velez M, Chen J, et al. Inborn errors of type I IFN immunity in patients with life-threatening COVID-19. Science. 2020;370(6515). 
17. Hart BJ, Dyall J, Postnikova E, Zhou H, Kindrachuk J, Johnson RF, et al. Interferon- $\beta$ and mycophenolic acid are potent inhibitors of Middle East respiratory syndrome coronavirus in cellbased assays. 2014;95(Pt 3):571.

18. Chan JF-W, Yao Y, Yeung M-L, Deng W, Bao L, Jia L, et al. Treatment With Lopinavir/Ritonavir or Interferon- $\beta 1 \mathrm{~b}$ Improves Outcome of MERS-CoV Infection in a Nonhuman Primate Model of Common Marmoset. The Journal of Infectious Diseases. 2015;212(12):1904-13.

19. Alavi Darazam I, Shokouhi S, Pourhoseingholi M, Naghibi Irvani S. Role of Interferon Therapy in Severe COVID-19: The COVIFERON Randomized Controlled Trial. 2020.

20. Ranieri VM, Pettilä V, Karvonen MK, Jalkanen J, Nightingale P, Brealey D, et al. Effect of intravenous interferon $\beta-1 \mathrm{a}$ on death and days free from mechanical ventilation among patients with moderate to severe acute respiratory distress syndrome: a randomized clinical trial. 2020;323(8):725-33.

21. Hung IF-N, Lung K-C, Tso EY-K, Liu R, Chung TW-H, Chu M-Y, et al. Triple combination of interferon beta-1 $\mathrm{b}$, lopinavir-ritonavir, and ribavirin in the treatment of patients admitted to hospital with COVID-19: an open-label, randomised, phase 2 trial. 2020;395(10238):1695-704.

22. Pan $\mathrm{H}$, Peto R, Karim QA, Alejandria $\mathrm{M}$, Restrepo $\mathrm{AMH}$, García $\mathrm{CH}$, et al. Repurposed antiviral drugs for COVID-19; interim WHO SOLIDARITY trial results. MedRxiv. 2020.

23. Torkildsen $\varnothing$, Myhr KM, B $\emptyset$ LJEjon. Disease-modifying treatments for multiple sclerosis-a review of approved medications. 2016;23:18-27.

24. Dastan F, Nadji SA, Saffaei A, Marjani M, Moniri A, Jamaati H, et al. Subcutaneous administration of Interferon beta-1a for COVID-19: A non-controlled prospective trial. 2020:106688.

25. Wu C, Chen X, Cai Y, Zhou X, Xu S, Huang H, et al. Risk factors associated with acute respiratory distress syndrome and death in patients with coronavirus disease 2019 pneumonia in Wuhan, China. JAMA internal medicine. 2020.

26. Sinha P, Calfee CS, Cherian S, Brealey D, Cutler S, King C, et al. Prevalence of phenotypes of acute respiratory distress syndrome in critically ill patients with COVID-19: a prospective observational study. The Lancet Respiratory Medicine. 2020.

27. Salzberger B, Glück T, Ehrenstein B. Successful containment of COVID-19: the WHO-Report on the COVID-19 outbreak in China. Infection. 2020;48(2):151-3.

28. Cao B, Wang Y, Wen D, Liu W, Wang J, Fan G, et al. A trial of lopinavir-ritonavir in adults hospitalized with severe Covid-19. New England Journal of Medicine. 2020.

29. Rieckmann P, O'Connor P, Francis GS, Wetherill G, Alteri EJDs. Haematological effects of interferon$\beta-1$ a (Rebif $\left.{ }^{\circledR}\right)$ therapy in multiple sclerosis. 2004;27(10):745-56.

\section{Tables}

Table 1. Characteristics of the Patients at Baseline* 


\begin{tabular}{|c|c|c|c|c|}
\hline Characteristic & $\begin{array}{l}\text { Total } \\
(\mathrm{N}=168)\end{array}$ & $\begin{array}{l}\text { Low-dose } \\
(\mathrm{N}=85)\end{array}$ & $\begin{array}{l}\text { High-dose } \\
(\mathrm{N}=83)\end{array}$ & $\begin{array}{l}\mathrm{P} \text { - } \\
\text { value }\end{array}$ \\
\hline Age (year) & $59.8(16.5)$ & $59.6(16.3)$ & $60.1(16.8)$ & 0.85 \\
\hline Male sex - no. (\%) & $104(61.9 \%)$ & $56(65.9 \%)$ & $48(57.8 \%)$ & 0.28 \\
\hline BMI (kg/m2) & $27.5(5.8)$ & $28.5(6.1)$ & 26.8 (5.5) & 0.08 \\
\hline $\begin{array}{l}\text { Duration of symptoms before } \\
\text { presentation }<7 \text { days }\end{array}$ & $137(81.5 \%)$ & $68(80.0 \%)$ & $69(83.1 \%)$ & 0.60 \\
\hline \multicolumn{5}{|l|}{ Past medical history } \\
\hline Diabetes & $45(26.8 \%)$ & $25(29.4 \%)$ & $20(24.1 \%)$ & 0.44 \\
\hline Hypertension & $62(37.3 \%)$ & $25(30.1 \%)$ & 37 (44.6\%) & 0.054 \\
\hline Ischemic Heart Disease & $31(18.7 \%)$ & $18(21.7 \%)$ & $13(15.7 \%)$ & 0.32 \\
\hline Congestive heart failure & $19(11.4 \%)$ & $13(15.7 \%)$ & $6(7.2 \%)$ & 0.09 \\
\hline Cerebrovascular accident (CVA) & $9(5.4 \%)$ & $2(2.4 \%)$ & $7(8.4 \%)$ & 0.09 \\
\hline Coronary Heart Disease & $25(14.9 \%)$ & $14(16.5 \%)$ & $11(13.3 \%)$ & 0.56 \\
\hline Chronic Kidney Disease & $14(8.3 \%)$ & & & \\
\hline Malignancy & $1(0.6 \%)$ & $1(1.2 \%)$ & $0(0.0 \%)$ & 0.32 \\
\hline Chronic Obstructive Pulmonary Disease & $2(1.2 \%)$ & $1(1.2 \%)$ & $1(1.2 \%)$ & 1.000 \\
\hline Asthma & $3(1.8 \%)$ & $0(0.0 \%)$ & $3(3.6 \%)$ & 0.08 \\
\hline \multicolumn{5}{|l|}{ Paramedical history } \\
\hline Anti-viral drug & $8(4.7 \%)$ & $3(3.5 \%)$ & $5(6 \%)$ & 0.48 \\
\hline Steroid & $2(1.1 \%)$ & $0(0.0 \%)$ & $2(2.4 \%)$ & 0.15 \\
\hline ACE \& ARB & $44(26.3 \%)$ & $15(17.9 \%)$ & $29(34.9 \%)$ & 0.012 \\
\hline \multicolumn{5}{|l|}{ Risk factors for severe disease } \\
\hline $\begin{array}{l}\text { RF Respiratory Rate >24/min } \\
\text { - no. (\%) }\end{array}$ & $103(61.3 \%)$ & $39(45.9 \%)$ & $64(77.1 \%)$ & $<0.001$ \\
\hline $\begin{array}{l}\text { RF Oxygen Saturation } \\
(\mathrm{SpO} 2)(<90 \%)\end{array}$ & $147(87.5 \%)$ & $69(81.2 \%)$ & $78(94.0 \%)$ & 0.012 \\
\hline RF D.dimer (>1000ng/ml) & $18(12.2 \%)$ & $2(3.1 \%)$ & $16(19.3 \%)$ & 0.003 \\
\hline RF CPK (> twice upper limit of normal) & $55(34.2 \%)$ & $28(35.4 \%)$ & 27 (32.9\%) & 0.74 \\
\hline
\end{tabular}




\begin{tabular}{|c|c|c|c|c|}
\hline RF CRP (>100 mg/liter) & $8(4.8 \%)$ & $8(9.6 \%)$ & $0(0.0 \%)$ & 0.004 \\
\hline RF LDH (>245 U/liter) & $148(95.5 \%)$ & $70(95.9 \%)$ & $78(95.1 \%)$ & 0.82 \\
\hline RF Lymphcount ( $0.8 \times 10^{-9} /$ liter $)$ & $65(39.2 \%)$ & $28(33.7 \%)$ & $37(44.6 \%)$ & 0.15 \\
\hline RF Ferritin $(>300 \mu \mathrm{g} / \mathrm{L})$ & $137(87.3 \%)$ & $61(82.4 \%)$ & $76(93.8 \%)$ & 0.027 \\
\hline Heart Rate (>125/min) & $69(41.1 \%)$ & $27(31.8 \%)$ & $42(50.6 \%)$ & 0.013 \\
\hline \multicolumn{5}{|l|}{ Respiratory factors } \\
\hline $\begin{array}{l}\text { Oxygen Saturation (Sp02) - median } \\
\text { (IQR) }\end{array}$ & $\begin{array}{l}84.0(76.0- \\
88.0)\end{array}$ & $\begin{array}{l}86.0(80.0- \\
88.0)\end{array}$ & $\begin{array}{l}83.0(70.0- \\
87.0)\end{array}$ & 0.006 \\
\hline $\begin{array}{l}\text { Venous PCO2, median } \\
\text { (IQR) }\end{array}$ & $\begin{array}{l}38.0(31.3- \\
45.0)\end{array}$ & $\begin{array}{l}38.0(30.2- \\
46.4)\end{array}$ & $\begin{array}{l}38.0(32.9- \\
44.0)\end{array}$ & 0.95 \\
\hline $\begin{array}{l}\text { Venous } \mathrm{HCO} \text {, median } \\
\text { (IQR) }\end{array}$ & $\begin{array}{l}24.9(22.1- \\
28.0)\end{array}$ & $\begin{array}{l}24.0(22.1- \\
28.0)\end{array}$ & $\begin{array}{l}25.0(22.0- \\
28.0)\end{array}$ & 0.88 \\
\hline \multicolumn{5}{|l|}{ White Blood Cell count ( $\times 10^{-9} /$ liter) } \\
\hline$<4 \times 10^{-9} /$ liter - no. $(\%)$ & $11(6.7 \%)$ & $6(7.4 \%)$ & $5(6.0 \%)$ & \multirow[t]{3}{*}{0.83} \\
\hline $4-10 \times 10^{-9} /$ liter - no. $(\%)$ & $97(59.1 \%)$ & $49(60.5 \%)$ & $48(57.8 \%)$ & \\
\hline$>10 \times 10^{-9} /$ liter - no. $(\%)$ & $56(34.1 \%)$ & $23(32.1 \%)$ & $30(36.1 \%)$ & \\
\hline $\begin{array}{l}\text { Lymphocyte count }\left(\times 10^{-9} / \text { liter) -median }\right. \\
\text { (IQR) }\end{array}$ & $\begin{array}{l}0.97(0.60- \\
1.49)\end{array}$ & $\begin{array}{l}0.92(0.60- \\
1.52)\end{array}$ & $\begin{array}{l}0.97(0.59- \\
1.42)\end{array}$ & 0.72 \\
\hline$\geq 1.0 \times 10^{-9} /$ liter - no. (\%) & $76(46.6 \%)$ & $37(45.7 \%)$ & 39 (47.6\%) & \multirow[t]{2}{*}{0.81} \\
\hline$<1.0 \times 10^{-9} /$ liter - no. $(\%)$ & 87 (53.4\%) & $44(54.3 \%)$ & $43(52.4 \%)$ & \\
\hline $\begin{array}{l}\text { Neutrophil count }\left(\times 10^{-9} / \text { liter }\right)-\text { median } \\
\text { (IQR) }\end{array}$ & $\begin{array}{l}6.75(4.21- \\
9.53)\end{array}$ & $\begin{array}{l}6.67(4.02- \\
9.33)\end{array}$ & $\begin{array}{l}6.75(4.29- \\
10.44)\end{array}$ & 0.40 \\
\hline$<1.5 \times 10^{-9} /$ liter - no. $(\%)$ & $1(0.6 \%)$ & $1(1.3 \%)$ & $0(0.0 \%)$ & \multirow[t]{3}{*}{0.61} \\
\hline $1.5-8 \times 10^{-9} /$ liter - no. $(\%)$ & 97 (63.0\%) & $49(62.8 \%)$ & $48(63.2 \%)$ & \\
\hline$>8 \times 10^{-9} /$ liter - no. $(\%)$ & $56(36.4 \%)$ & $28(36.8 \%)$ & $28(36.8 \%)$ & \\
\hline $\begin{array}{l}\text { Platelet count }\left(\times 10^{-9} / \text { liter }\right)-\text { median } \\
\text { (IQR) }\end{array}$ & $\begin{array}{l}198.0(148.5- \\
272.0)\end{array}$ & $\begin{array}{l}180.5(134.5- \\
230.5)\end{array}$ & $\begin{array}{l}222(153- \\
315)\end{array}$ & 0.88 \\
\hline$\geq 100 \times 10^{-9} /$ liter - no. $(\%)$ & 151 (91.5\%) & 76 (92.7\%) & 75 (90.4\%) & 0.59 \\
\hline
\end{tabular}




\begin{tabular}{|c|c|c|c|c|}
\hline$<100 \times 10^{-9} /$ liter - no. $(\%)$ & $14(8.5 \%)$ & $6(7.3 \%)$ & $8(9.6 \%)$ & \\
\hline $\begin{array}{l}\text { Serum Creatinine ( } \mu \mathrm{mol} / \text { liter }) \text { - median } \\
(\mathrm{IQR})\end{array}$ & $\begin{array}{l}110(100- \\
140)\end{array}$ & $\begin{array}{l}110(100- \\
140)\end{array}$ & $\begin{array}{l}110(100- \\
140)\end{array}$ & 0.99 \\
\hline$\leq 133$ pmol/liter - no. (\%) & $122(73.1 \%)$ & $61(72.6 \%)$ & $61(73.5 \%)$ & \multirow[t]{2}{*}{0.89} \\
\hline$>133$ pmol/liter - no. (\%) & $45(26.9 \%)$ & $23(26.5 \%)$ & $22(26.5 \%)$ & \\
\hline $\begin{array}{l}\text { Aspartate Aminotransferase (AST) } \\
\text { (U/liter) - median (IQR) }\end{array}$ & $\begin{array}{l}55(41.7- \\
80.5)\end{array}$ & $54(40-80)$ & $55(42-82)$ & 0.41 \\
\hline$\leq 40$ U/liter - no. (\%) & $37(22.3 \%)$ & $21(25.3 \%)$ & $16(19.3 \%)$ & \multirow[t]{2}{*}{0.35} \\
\hline >40 U/liter - no. (\%) & $129(77.7 \%)$ & $62(74.7 \%)$ & $67(80.7 \%)$ & \\
\hline $\begin{array}{l}\text { Alanine Aminotransferase (ALT) (U/liter) } \\
\text { - median (IQR) }\end{array}$ & $\begin{array}{l}44.5(25.2- \\
69.5)\end{array}$ & $42(25-54)$ & $49(25-95.5)$ & 0.07 \\
\hline$\leq 50 \mathrm{U} /$ liter - no. (\%) & $98(59.8 \%)$ & $56(67.5 \%)$ & $42(51.9 \%)$ & \multirow[t]{2}{*}{0.04} \\
\hline$>50$ U/liter - no. (\%) & $66(40.2 \%)$ & $27(32.5 \%)$ & $39(48.1 \%)$ & \\
\hline $\begin{array}{l}\text { Lactate Dehydrogenase (LDH) (U/liter) - } \\
\text { median (IQR) }\end{array}$ & $\begin{array}{l}583(416- \\
779)\end{array}$ & $\begin{array}{l}563(418- \\
765.5)\end{array}$ & $\begin{array}{l}656(411.5- \\
784)\end{array}$ & 0.42 \\
\hline$\leq 245$ U/liter - no. (\%) & $7(4.5 \%)$ & $3(4.1 \%)$ & $4(4.9 \%)$ & \multirow[t]{2}{*}{0.82} \\
\hline >245 U/liter - no. (\%) & $148(95.5 \%)$ & $70(95.9 \%)$ & $78(95.1 \%)$ & \\
\hline $\begin{array}{l}\text { Blood Urea Nitrogen (BUN) - median } \\
\text { (IQR) }\end{array}$ & $42(30.7-61)$ & $45(33-60.7)$ & $\begin{array}{l}39.5(25.7- \\
64)\end{array}$ & 0.22 \\
\hline C-Reactive Protein (CRP) - median (IQR) & $\begin{array}{l}48(28.9- \\
63.7)\end{array}$ & $\begin{array}{l}52(33.5- \\
73.6)\end{array}$ & $\begin{array}{l}45(26.4- \\
55.4)\end{array}$ & 0.013 \\
\hline CRP<6 - no. (\%) & $6(4.8 \%)$ & $3(5.3 \%)$ & $3(4.3 \%)$ & \multirow[t]{2}{*}{0.81} \\
\hline CRP>6 - no. (\%) & $120(95.2 \%)$ & 54 (94.7\%) & 66 (95.7\%) & \\
\hline $\begin{array}{l}\text { Erythrocyte Sedimentation Rate (ESR) - } \\
\text { median (IQR) }\end{array}$ & $50(38-65)$ & $\begin{array}{l}47.5(28.2- \\
60)\end{array}$ & $53(44-66)$ & 0.09 \\
\hline
\end{tabular}

The values shown are based on available data. Value for D.dimer was available for 64 , values for CPK was available for 79 patients and values for DLH was available for 80 patients in low dose group. Values for Erythrocyte Sedimentation Rate was available for 60 patients in low dose group and 63 patients in high dose group. Quantitative measures were compared using the Mann-Whitney U test or (if normally distributed) T-test. Categorical variables were compared using the Chi-Square test or Fisher exact test. 


\begin{tabular}{|c|c|c|c|c|c|c|}
\hline & $\begin{array}{l}\text { Total } \\
(\mathrm{N}=168)\end{array}$ & $\begin{array}{l}\text { Low-dose } \\
(\mathrm{N}=85)\end{array}$ & \multicolumn{2}{|c|}{ High-dose $(\mathrm{N}=83)$} & \multicolumn{2}{|c|}{ P-value } \\
\hline Mortality at day $21-$ no. (\%) & $\begin{array}{l}65 \\
(38.7 \%)\end{array}$ & $\begin{array}{l}31 \\
(36.5 \%)\end{array}$ & \multicolumn{2}{|c|}{$34(41.0 \%)$} & \multicolumn{2}{|c|}{0.55} \\
\hline $\begin{array}{l}\text { Hospital stay - median no. of days } \\
\text { (IQR) }\end{array}$ & $8(6-9)$ & $6(5-7)$ & \multicolumn{2}{|c|}{$10(8-12)$} & \multicolumn{2}{|c|}{0.018} \\
\hline \multicolumn{7}{|l|}{ Respiratory factors } \\
\hline $\begin{array}{l}\text { Oxygen Saturation (Worst) (Sp02) } \\
\text { - median (IQR) }\end{array}$ & $\begin{array}{l}78.0 \\
(62.0- \\
84.0)\end{array}$ & $\begin{array}{l}80.5 \\
(64.0- \\
86.2)\end{array}$ & \multicolumn{2}{|c|}{$75.0(60.0-82.0)$} & \multicolumn{2}{|c|}{0.017} \\
\hline $\begin{array}{l}\text { Oxygen Saturation (Discharge) } \\
\text { (SpO2) - median (IQR) }\end{array}$ & $\begin{array}{l}91.0 \\
(88.7- \\
93.0)\end{array}$ & $\begin{array}{l}92.0 \\
(89.0- \\
94.5)\end{array}$ & \multicolumn{2}{|c|}{$90.0(88.0-92.0)$} & \multicolumn{2}{|c|}{0.017} \\
\hline $\begin{array}{l}\text { Venus Pco2 (Discharge) - median } \\
\text { (IQR) }\end{array}$ & $\begin{array}{l}41.0 \\
(38.0- \\
45.4)\end{array}$ & $\begin{array}{l}41.0 \\
(39.0- \\
44.0)\end{array}$ & \multicolumn{2}{|c|}{$41.0(36.8-50.0)$} & \multicolumn{2}{|c|}{0.61} \\
\hline $\begin{array}{l}\text { Venus Hco3(Discharge) - median } \\
\text { (IQR) }\end{array}$ & $\begin{array}{l}25.8 \\
(24.1- \\
27.0)\end{array}$ & $\begin{array}{l}25.0 \\
(25.0- \\
27.0)\end{array}$ & \multicolumn{2}{|c|}{$25.8(22.1-27.0)$} & \multicolumn{2}{|c|}{0.48} \\
\hline \multicolumn{7}{|l|}{ White Blood Cell count $\left(\times 10^{-9} /\right.$ liter) } \\
\hline$<4 \times 10^{-9} /$ liter - no. (\%) & $\begin{array}{l}22 \\
(13.4 \%)\end{array}$ & $14(16.9 \%)$ & & $8(9.9 \%)$ & \multirow{3}{*}{\multicolumn{2}{|c|}{0.22}} \\
\hline $4-10 \times 10^{-9} /$ liter - no. (\%) & $\begin{array}{l}90 \\
(54.9 \%)\end{array}$ & $47(56.6 \%)$ & & $43(53.1 \%)$ & & \\
\hline$>10 \times 10^{-9} /$ liter - no. $(\%)$ & $\begin{array}{l}52 \\
(31.7 \%)\end{array}$ & $22(26.5 \%)$ & & $30(37.0 \%)$ & & \\
\hline $\begin{array}{l}\text { Lymphocyte count }\left(\times 10^{-9} / \text { liter }\right)- \\
\text { median (IQR) }\end{array}$ & $\begin{array}{l}0.88 \\
(0.54- \\
1.51)\end{array}$ & \multicolumn{2}{|c|}{$0.97(0.58-1.42)$} & \multicolumn{2}{|l|}{$0.89(0.56-1.48)$} & 0.83 \\
\hline$\geq 1.0 \times 10^{-9} /$ liter - no. $(\%)$ & $\begin{array}{l}66 \\
(41.5 \%)\end{array}$ & \multicolumn{2}{|l|}{$36(43.9 \%)$} & $30(39.0 \%)$ & & \multirow[t]{2}{*}{0.53} \\
\hline$<1.0 \times 10^{-9} /$ liter - no. $(\%)$ & $\begin{array}{l}93 \\
(58.5 \%)\end{array}$ & $46(56.1 \%)$ & & $47(61.0 \%)$ & & \\
\hline $\begin{array}{l}\text { Platelet count }\left(\times 10^{-9} / \text { liter }\right)- \\
\text { median (IQR) }\end{array}$ & $\begin{array}{l}207(146- \\
279)\end{array}$ & $208(160-275.2$ & & $198(142-280)$ & & 0.39 \\
\hline \multirow[t]{2}{*}{$\geq 100 \times 10^{-9} /$ liter - no. (\%) } & $\begin{array}{l}152 \\
(93.3 \%)\end{array}$ & 77 (93.95\%) & & $75(92.6 \%)$ & & \multirow[t]{2}{*}{0.74} \\
\hline & $11(6.7 \%)$ & $5(6.1 \%)$ & & $6(7.4 \%)$ & & \\
\hline
\end{tabular}




\begin{tabular}{|c|c|c|c|c|}
\hline $\begin{array}{l}\text { Neutrophil count }\left(\times 10^{-9} / \text { liter }\right)- \\
\text { median (IQR) }\end{array}$ & $\begin{array}{l}6.22 \\
(4.07- \\
9.25)\end{array}$ & $5.50(3.61-8.32)$ & $6.85(4.65-9.74)$ & 0.10 \\
\hline$<1.5 \times 10^{-9} /$ liter - no. $(\%)$ & $5(3.3 \%)$ & $1(1.3 \%)$ & $4(5.4 \%)$ & \multirow[t]{3}{*}{0.19} \\
\hline $1.5-8 \times 10^{-9} /$ liter - no. (\%) & $\begin{array}{l}95 \\
(62.5 \%)\end{array}$ & $53(67.9 \%)$ & $42(56.8 \%)$ & \\
\hline$>8 \times 10^{-9} /$ liter - no. $(\%)$ & $\begin{array}{l}52 \\
(34.2 \%)\end{array}$ & $24(30.8 \%)$ & $28(37.8 \%)$ & \\
\hline $\begin{array}{l}\text { C-Reactive Protein (CRP) - median } \\
\text { (IQR) }\end{array}$ & $\begin{array}{l}55 \\
(41.8 .-73)\end{array}$ & $66.1(45-83)$ & $51.9(36.1-62.7)$ & 0.004 \\
\hline CRP<6 - no. (\%) & $4(2.9 \%)$ & $2(2.8 \%)$ & $2(2.9 \%)$ & \multirow[t]{2}{*}{0.96} \\
\hline CRP>6 - no. (\%) & $\begin{array}{l}135 \\
(97.1 \%)\end{array}$ & $69(97.2 \%)$ & $66(97.1 \%)$ & \\
\hline $\begin{array}{l}\text { Erythrocyte Sedimentation Rate } \\
\text { (ESR) - median (IQR) }\end{array}$ & $\begin{array}{l}53.5(40- \\
68)\end{array}$ & $50(30.5-69.2)$ & $59(44.2-68.0)$ & 0.17 \\
\hline
\end{tabular}

*Values for HCT was available for 76 patients in low dose group and 79 patients in high dose group. Values for Erythrocyte Sedimentation Rate was available for 62 patients in low dose group and 64 patients in high dose group. Quantitative measures were compared using the Mann-Whitney U test or (if normally distributed) T-test. Categorical variables were compared using the Chi-Square test or Fisher exact test.

Table 3. Adverse Events in the Safety Population. * 


\begin{tabular}{|llll|}
\hline Event & $\begin{array}{l}\text { Low-dose } \\
(\mathrm{N}=85)\end{array}$ & $\begin{array}{l}\text { High-dose } \\
(\mathrm{N}=83)\end{array}$ & \\
\hline Adverse Event & & & P Value \\
\hline Nausea & $16(19.0 \%)$ & $17(20.5 \%)$ & 0.82 \\
\hline Vomiting & $5(6.0 \%)$ & $4(4.8 \%)$ & 0.73 \\
\hline Diarrhea & $10(11.8 \%)$ & $9(10.8 \%)$ & 0.85 \\
\hline Abdominal pain & $14(16.5 \%)$ & $10(12.0 \%)$ & 0.41 \\
\hline Rash & $3(3.5 \%)$ & $11(13.3 \%)$ & 0.023 \\
\hline Raised LFT & $29(34.1 \%)$ & $29(34.9 \%)$ & 0.91 \\
\hline Hyperbilirubinaemia & $19(22.6 \%)$ & $20(24.1 \%)$ & 0.82 \\
\hline Increased Creatinine & $22(25.9 \%)$ & $21(25.3 \%)$ & 0.93 \\
\hline Leukopenia & $22(26.2 \%)$ & $7(8.4 \%)$ & 0.002 \\
\hline Anemia & $28(33.3 \%)$ & $26(31.3 \%)$ & 0.78 \\
\hline Hypo.Albuminemia & $9(11.3 \%)$ & $2(2.4 \%)$ & 0.024 \\
\hline Rised CPK & $14(16.7 \%)$ & $12(14.6 \%)$ & 0.72 \\
\hline Lymphopenia & $15(17.6 \%)$ & $14(16.9 \%)$ & 0.89 \\
\hline Serious Adverse Event & $0(0.0 \%)$ & $0(0.0 \%)$ & $\ldots$ \\
\hline Acute Respiratory Distress Syndrome (ARDS) & $27(31.8 \%)$ & $33(39.8 \%)$ & 0.28 \\
\hline Acute Kidney Failure (AKI) & $15(17.6 \%)$ & $11(13.3 \%)$ & 0.43 \\
\hline Secondary Infection & $5(5.9 \%)$ & $8(9.6 \%)$ & 0.36 \\
\hline Shock & $21(24.7 \%)$ & $15(18.1 \%)$ & 0.29 \\
\hline Severe Anemia & $17(20.0 \%)$ & $6(7.3 \%)$ & 0.02 \\
\hline Acute gastritis & $1(1.2 \%)$ & $0(0.0 \%)$ & 0.32 \\
\hline Lower GI bleeding & $1(43.9 \%)$ & 0.80 \\
\hline Sepsis & $3(3.6 \%)$ & 0.30 \\
\hline Pneumothorax & & & \\
\hline
\end{tabular}

*Adverse events that occurred in more than one patient after randomization through day 21 are shown. Some patients had more than one adverse event. 


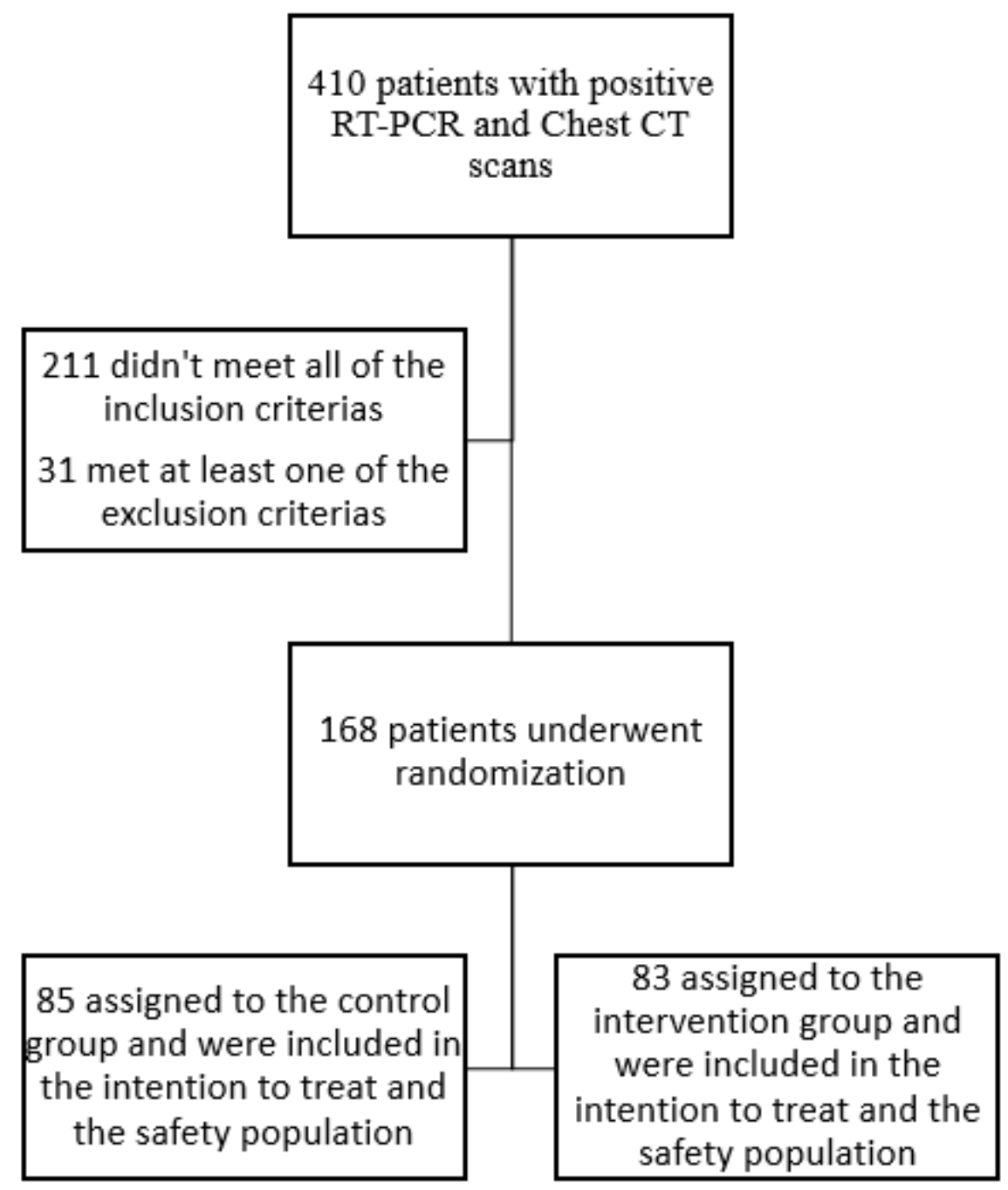

Figure 1

Trial Flow Diagram

\section{Supplementary Files}

This is a list of supplementary files associated with this preprint. Click to download.

- CONSORT2010Checklist.R.doc 